\title{
A Reflection on Special Challenges and Amending Pedagogy in Clinical Social Work Practice Courses During the COVID-19 Pandemic
}

\author{
David B. Wohlsifer ${ }^{1}$ (i) $\cdot$ Laurie Patlin Suttenberg ${ }^{1}$ (i) $\cdot$ Juyoung Park ${ }^{1}$ (i) \\ Accepted: 9 August 2021 / Published online: 17 August 2021 \\ (c) The Author(s), under exclusive licence to Springer Science+Business Media, LLC, part of Springer Nature 2021
}

\begin{abstract}
Due to the COVID-19 pandemic, many social work students and educators had to switch gears quickly and replace faceto-face courses with online delivery. While most had had experience with remote learning, the unexpected and immediate transition was challenging. Students and educators who had chosen in-person instruction had to adapt quickly to a learning paradigm for which they had not planned, while simultaneously coping with the anxieties brought on by the pandemic, such as economic hardships, threat of illness, and new family responsibilities. The pandemic has engendered fear, trauma, grief, and loss, all of which negatively affect instruction and learning. This reflection paper identifies special challenges and issues with regard to teaching and learning in social work clinical practice courses brought on by the pandemic. Utilizing the theoretical frameworks of ambiguous loss, interpersonal neurobiology, and the here and now approach, this paper suggests effective teaching methods and collaborative learning strategies to inform social work education during academic disruption in this and future emergencies (e.g., natural disasters). It is suggested that social presence, as well as group cohesion among students and between students and instructors, can serve as a protective factor to ensure continued productive motivation for teaching and learning while facing the challenges that are experienced during such times.
\end{abstract}

Keywords COVID-19 $\cdot$ Social work education $\cdot$ Emergency educational plan $\cdot$ Social presence $\cdot$ Online education/online learning

Coronavirus disease 2019 (COVID-19), caused by severe acute respiratory syndrome coronavirus 2 (SARS-CoV-2), quickly became a global pandemic that has resulted in $3 \%$ global case mortality, which is much higher than the mortality rate for influenza which is approximately $0.05 \%$ (Andersen et al., 2020; Wang et al., 2020; Zhang et al., 2020). In the United States, there has been a dramatic increase in the number of COVID-19 cases and deaths associated with its complications since the first case in January 2020 in the state of Washington (Holshue et al., 2020; Murphy, 2020).

Due to the high contagion of this disease, possibly spread even by people who are asymptomatic, it is required to practice social distancing to reduce interpersonal contact and community transmission (Centers for Disease Control \& Prevention, 2020). This has resulted in changes in lifestyle

David B. Wohlsifer

dlandsmanwohlsif@fau.edu

1 Phyllis and Harvey Sandler School of Social Work, Florida Atlantic University, Boca Raton, FL 33431-0900, USA and shutdowns of daily functions (Galea et al., 2020). The pandemic has led to an economic downturn marked by reduction in work hours, job loss, inability to seek health care, and loss of health insurance and other benefits (Gangopadhyaya \& Garrett, 2020). In addition to the economic crisis, many feel isolated due to social distancing, which is strongly associated with pandemic-related emotional distress such as depression and anxiety (Holmes et al., 2020). Many people have had close personal experiences with COVID-19 as they may have contracted it and/or have observed those close to them suffering and even dying from the disease.

COVID-19 caused the closure of schools all over the world. At the time of writing this article, the pandemic has engendered fear, trauma, grief, and loss, all of which can negatively impact instruction and learning. In an effort to decrease infection rates at the onset of the pandemic, most educational institutions, including schools of social work, immediately moved all learning to emergency remote teaching. In contrast to learning experiences that are carefully planned for online delivery, emergency remote teaching is a temporary shift from on-campus learning to an alternative 
delivery method due to crisis situations such as natural disasters (Hodges et al., 2020). In the case of COVID-19, uncertainty associated with the disease itself and the absence of reliable treatment shaped the emergency educational plan (Murphy, 2020). Both students and educators were challenged to adapt to an unexpected learning paradigm while coping with anxieties brought on by the pandemic, such as economic hardships, threat of illness, and new family responsibilities. This was a particular challenge in clinically oriented in-person practice courses, as class time and assignments often utilize live, real-time interactions such as role play, interviews, presentations, and various arrays of group discussions as primary means of accomplishing learning objectives.

To continue the semester's work online, conferencing applications, such as Cisco Webex or Zoom, were utilized to provide real-time face-to-face interactions. Lectures, as well as interactive learning activities such as small group discussions, presentations, and role plays, continued during the pandemic situation by use of these platforms. Synchronous communication tools such as text chat and shared whiteboard added to the quality of the classes (Falloon, 2012; Holmes et al., 2015). However, limitations in synchronous instruction online have been identified (Falloon, 2012; Nedeva et al., 2014). Abrupt transitions to online education can be problematic for students who were originally not prepared or who were not planning to take their classes in this format.

Many educators who were forced by pandemic restrictions to convert their courses to online learning did not have the expertise required for online teaching and learning pedagogy (Petzold, 2020), in particular those who had no previous online teaching experience. In addition to the technological challenge for educators, not all students have access to the level of technology required for online learning. Some may not have financial resources to procure what is necessary. Internet signals might not be adequate where they live. Students may be sharing computers with other household members and therefore may not be able to use the devices during class time because someone else is using them. Privacy to participate in online classes may also be an issue.

Several studies on social work education during the COVID-19 pandemic have been conducted (Dove, 2021; Hutchison, 2021; Karabanow, 2021; McCarthy et al., 2021; Sapiro, 2021; Sethi, 2021; Smoyer et al., 2020). Most of the studies identified challenges faced by both educators and students, although it was reported that educators were pleased to be able to continue to teach (McCarthy et al., 2021). However, the literature has highlighted concerns about the quality of teaching in online classes, resulting from converting the in-class course to online without the teacher being fully prepared. Thus, the online environment has not fully satisfied course objectives or students' expectations.
Students have been less exposed to professional dialogue and interactions, have been less stimulated to internalize social work values and ethics (McCarthy et al., 2021), and have had fewer opportunities to enhance critical thinking skills. Smoyer et al. (2020) conducted a survey of Bachelor of Social Work (BSW) students about their experiences with online courses during the pandemic. Findings indicated that the BSW students expressed frustration with distance education; they reported limited opportunity to ask instructors questions about course content or assignments. This was particularly true for those who were taking asynchronous online courses. Hands-on activities or learning experiences and the physical closeness in the classroom were missing in online class. Smoyer et al. emphasized the need for interactive technology in online social work classes to stimulate personal interactions and immediate feedback from the instructor and peers to motivate students to participate actively (Smoyer et al., 2020).

This reflection paper applies the theoretical frameworks of ambiguous loss, interpersonal neurobiology, and the here and now approach to understand the affective experiences of COVID-19 in social work education at the onset of the pandemic. Launching from the perspectives of these three theories, this paper discusses effective online teaching methods and collaborative learning strategies in clinical social work practice courses during the period of academic disruption caused by the onset of the COVID-19 pandemic that may be useful in future emergencies. Class activities, teaching methods, and collaborative learning strategies that emphasize social presence and group cohesion amongst students emerged at this time to be the best practices for maintaining a productive learning environment.

\section{Case Example: Clinical Social Work with Families, Second-Year}

\section{MSW Clinical Practice Course, Spring Semester 2020}

A special energy comes over a college or university as students and faculty move toward the second half of the spring semester. In particular, among those who will be graduating, there is a growing excitement with regard to upcoming transitions and events that will mark the formal end of this part of their academic journey. They begin to make plans for graduation day. In schools of social work, students begin the termination process with clients at their field placements. Extensive time in the field, classes, writing papers, doing group projects, and giving presentations are coming to an end as they start to draft their first Master of Social Work (MSW) resumes and consider next steps for jobs, supervision, and continued professional education. Faculty members delight in welcoming graduates to the profession at the 
end of spring semester.... and then it all changed in midMarch 2020.

At that time one of the authors was teaching a secondyear, MSW-level family therapy class. A portion of class time was dedicated each week to group process. As a means of understanding the concept of a "system," the instructor sought to create a professional holding environment in the class that would serve as a parallel process to the experience of being a part of a family system. After each group process discussion, time was dedicated for reflective meta conversations about process, as opposed to the content of the group interactions. Students bridged these ideas back to their own work with clients, expanding their vision of what occurs between social worker and client(s) well beyond diagnosis and treatment. The extent to which this practice would benefit the students would be revealed once the transition to remote learning began.

Due to the quick onset of the COVID-19 pandemic in March 2020, the university moved all in-person classes to an online format. This change occurred with less than a week's notice. In addition to classes moving online, nearly all field placement assignments were halted immediately and most students did not know whether or when they would return to their agencies. Following the instructions of the university's administration, the instructor met with the students at the regularly scheduled time on Cisco Webex instead of in the usual classroom, and students were given the option to continue the course asynchronously online or as a synchronous online class through Cisco Webex. Unanimously, the students chose to continue in a synchronous online format at the regularly scheduled day and time. The class then proceeded, similarly as in previous classes, utilizing the first $10-15$ min of class for group process.

As students began their first Cisco Webex class, the typical 15-min exchange became a 2-h conversation. Something much bigger had occurred for the students than simply moving the class online. The students needed to talk. They needed to listen and be heard. They needed to externalize their experiences and have them witnessed. Not tending to these needs would not have had merely an adverse impact on the learning process; it would have halted it. What had been established as a holding environment for the sake of learning began to morph into a space for sharing, concern, uncertainty, pain, and healing. The class had begun its transition from an in-person holding environment to a virtual holding environment, which is present when a group uses technology to maintain connections (Fletcher et al., 2014; Shulman, 2000).

\section{Ambiguous Loss and the COVID-19 Pandemic}

Pauline Boss's (Boss \& Couden, 2002) concept of ambiguous loss provides a framework to understand the emotional experience of the COVID-19 pandemic's impact on the class described above and likely what most students and faculty experience at times of academic disruption due to acute crises. Boss and Couden (2002) defined ambiguous loss as "a situation where a loved one is perceived as physically present while psychologically absent, or physically absent but kept psychologically present because their status as dead or alive, dying, or in remission, remains unclear" (p. 1352).

For the social work students in spring 2020, while no one person was missing, there were multiple layers of loss and ambiguity. School communities that had been rich with connection and had become dependable and predictable holding environments were now in question. Rites of passage, such as finishing the year with classmates, terminating with clients and supervisors at field placements, celebration and closure with the faculty and staff, finishing academic work, the induction ceremony, and graduation, were now in limbo. Would they even be able to complete their degrees in May, as planned? All of this was occurring for the students in tandem with the impending horror of the pandemic. Students were worried about whether they or their loved ones would be sick or even die. Ongoing news footage painted a dire picture of the world situation, showing critically ill people, exhausted care providers, full morgues, and coffins awaiting burial in places, such as China and Italy, that were being ravaged by COVID-19.

Our premise is that the most stressful losses are those that are ambiguous. When people are unable to obtain clarity about the status of a family member, they are often immobilized: decisions are put on hold; roles remain unclear; relationship boundaries are confusing; celebrations and rituals are canceled. (Boss \& Couden, 2002, p. 1352)

Not only when people cannot obtain clarity about the status of a family member but also when they cannot obtain clarity about the status of what gives their lives fulfillment, purpose, structure, and meaning, they are immobilized and suffer strong anxiety. Echoing Boss and Couden's comments, everything was now on hold due to COVID-19. No one knew what to expect next or what else would be "cancelled." Faculty members were not immune to the ambiguity and challenges that the students were facing; they were experiencing them, too.

\section{Perspectives From Interpersonal Neurobiology}

In tandem with the perspective of ambiguous loss, interpersonal neurobiology provides a framework for understanding what can occur when students and educators must deal with adversities or natural disasters that lead to academic disruption, such as the COVID-19 pandemic. When faced with what the brain perceives as danger or threat, 
the immediate neurobiological response is to go to flight, fight, or freeze (Cozolino, 2014). This can result in panic, which can be contagious, as when someone yells "fire" or what sounds like a shot is heard. The event catches everyone's attention and is likely to lead to increased alertness, as people scan for danger. Emergencies of any type that can lead to academic disruption can have the same neurobiological impact as the sound of the shot or warning about fire. From the neurobiological perspective, people recognize the interruption as a threat and therefore move into a state of heightened arousal. The functions in the brain move from the frontal cortex, where one thinks, to the amygdala, a more primitive location that is wired to respond to danger, sending messages to the body to prepare for battle, to run, or to freeze (Cozolino, 2014). As Fishbane (2007) wrote, "We share with all animals the instinct for self-preservation" (p. 297).

Many educators found their students in this shared state of neurobiological arousal in spring 2020; they shared that state. It is noted throughout the literature (e.g., Cozolino, 2014; Fishbane, 2007) that connection to others can serve as a remedy for the emotional stress in such situations. As Fishbane (2007) wrote, "Social connections facilitate survival in primates" (p. 398). When one is threatened, being part of a group is a neurologically adaptive resource. Cozolino (2006, as cited in Fishbane, 2007) commenting on this dynamic stated, "Our social brains have been shaped by natural selection because being social enhances survival" (p. 397). Connection to others leads to release of the neurotransmitter oxytocin, which reduces the impact of stress hormones such as cortisol and norepinephrine (Fishbane, 2013). "Pairing, attachment, and feeling safe all release oxytocin and are strengthened by it" (Fishbane, 2007, p. 406).

In the case example above, the sense of attachment, safety, and group cohesion, originally achieved in the faceto-face class and later strengthened as the group changed their regularly scheduled in-person class sessions to an online format, became an interpersonal neurobiological remedy to stress, isolation, ambiguous loss, and fear, as it served as a protective and healing mechanism for the students. This is why the students needed more than 15 min for the group processing time at the beginning of the first synchronous online class. The group processing period in each class had already been established as an interpersonal neurobiological resource; therefore, instinctively and unconsciously, students were drawing on an established group coping mechanism to deal with the stressors related to the pandemic. Social work educators may be unaware of the magnitude of the simple but powerful resource of allowing time for group processing in both face-to-face and online classes. This situation clearly demonstrated the value of the time allotted for group processing as an effective online teaching method and strategy during the period of academic disruption.

\section{Amending Pedagogy in the Learning Environment: Use of Here and Now}

Maintaining academic momentum and student engagement in the learning process mid-semester when confronted with a seismic shift in course delivery caused not only emotional challenges, as noted above, but also a major pedagogical challenge. The clinical skills of seasoned clinicians who teach advanced social work clinical practice courses were a resource for assessing the situation in which the students found themselves due to COVID-19. It was apparent that many of the struggles that bring people to therapy, such as loss, ambiguous loss, fear, relationships, and interpersonal struggles, were playing out in the classroom setting. Just as therapeutic goals are often impeded or deferred by unforeseen occurring events, this was happening in the social work classroom. As clinicians must guide clients through rough waters, offering advice and support to maintain equilibrium during times of upheaval, this same necessity presented at this time.

The group process time in the class described above demonstrated utilization of a here and now approach when working with groups. Yalom and Leszcz (2005) defined the concept of working with groups in the here and now as addressing "what is happening in this room in the immediate present" (p. 30), drawing the participants' attention not only to what is being said (content) but also to all that is going on beyond just the words being exchanged (process). For a group to be effective, "the group members must experience one another with as much spontaneity and honesty as possible, and they must also reflect back on that experience" (p. 30). This duality of the here and now has utility both in the consulting room and in the classroom. Kivlighan (2014) wrote that, in therapy, "here and now interventions tend to open the client up to deeper levels of emotional experiencing" (p. 20).

While facing the impact of the COVID-19 pandemic, students' "emotional experiencing" was heightened in response to a community that was quickly unraveling around them. Joining with peers in sharing the collective here and now emotional experience strengthened the cohesion that had been already established among the students. The living rooms, bedrooms, pets, children, patios, and backyards that became the new backdrop on students' computer screens replaced the familiar classroom environment and offered opportunity for a more personal dimension to enhance class intimacy.

While conversations on Internet platforms such as Cisco Webex or Zoom are limited in terms of eye contact and the ability to see other participants easily on the screen, use of the chatbox was a positive teaching resource to address this issue. Chatbox features can be found on almost all web-based meeting platforms. The chatbox was a venue 
for continuous engagement. During times of sharing, either with the instructor's prompting or of their own accord, students and the instructor shared thoughtful and emotionally supportive messages with classmates. A frequent statement from the instructor in the case example above when using the chat box feature was, "You are getting a lot of support in the chat box." While the phrase soon became a humorous cliché that engendered laughter, it also led to moments of quiet reflection in which the student who had just spoken could receive supportive feedback from classmates. Utilizing the here and now provided an additional interpersonal neurobiological resource to the students to enhance connection and decrease stress.

\section{Ritual and Ceremony as Components of the Educational Experience}

Abrupt endings to any group process are ill advised. Groups need something to mark their termination. On the last day of class in the family-focused practice course described in the case example, students were asked to present an original poem, do a performance of some sort, or in some other creative way convey to the class the role that "family" had for them in either their personal lives or in their work with clients. In fulfillment of this assignment, one student played music for the class. He spun a mix of records that integrated the classic "Pomp and Circumstance" graduation song.

Having the advantage of seeing the students' faces on Cisco Webex, the instructor noticed that the melody brought several of them to tears. The instructor knew that the students were upset that their graduation ceremony had been canceled. "Celebrations and rituals are canceled" in situations of ambiguous loss (Boss \& Couden, 2002, p. 1352). Having recognized what the students were feeling, the instructor gave them time to process it and then called for a 10-min break. He told the class that he had to prepare for his "performance" contribution.

He returned to the class after the break wearing his graduation regalia. He sensed that the class needed to hear their names read aloud in a format that resembled a graduation ceremony. Walsh (2009) wrote that "rituals and ceremonies serve invaluable functions in connecting individuals with their families and communities, as well as guiding them through life-passage and times of adversity" (p. 14). The class laughed when the instructor surprised them in his regalia. He said, simply, "This is my gift to you, the closest I can approximate to the graduation you missed." Then he read each of their names slowly and clearly. Many students were crying.

Later that evening, he saw that many of them had posted screenshots of the "virtual graduation" to social media, where they received congratulatory responses. The "ceremony," with its ritual sounds and symbols, although not likely in the format that they had imagined in the early part of the semester, marked the achievement of their degrees and validated their perseverance in the face of adversity.

\section{Discussion}

This reflection paper gives voice to one moment in time. This experience of academic disruption due the COVID-19 pandemic, which continues to rage at the time this paper is written, adds to the knowledge base in the field by providing social work educators an example of how to think about and maintain a productive learning environment during such times. It documents the affective and pedagogical experiences of the impact of the COVID-19 pandemic in spring 2020. However, the events of this period are isomorphic and can be applied to many future situations of acute academic disruption. This paper suggests effective teaching methods and collaborative learning strategies, utilizing the theoretical frameworks of ambiguous loss, interpersonal neurobiology, and the here-and-now approach for understanding the experiences of students and faculty when faced with unique obstacles, problems, and issues in instruction and learning. Unlike scheduled in-person or online courses that have been planned and prepared in advance of the semester, the abrupt migration to emergency remote teaching utilizing online delivery in the context of living in the midst of a global pandemic produced challenges to both students and educators.

In times such as those described in this paper, in which the learning environment is disrupted, the most effective teaching methods for clinical practice courses, as well as for responding to student distress, should promote social presence, which is defined as the level to which a student feels connected to other students and the instructor in the online learning community (Sung \& Mayer, 2012; Tu \& McIsaac, 2002). Social presence can decrease anxiety (Fishbane, 2007) and increase group cohesion, which is a useful resource during times of stress. Social presence was the critical factor that sustained the class in the example above.

At times of academic disruption, a synchronous approach is recommended over an asynchronous format for teaching online clinical social work practice courses in order to generate immediate responses/feedback from the instructor, reduce isolation, and increase group cohesion and social presence in order to achieve the same level of learning effects that are experienced in in-person classes. Since speaking aloud can present multiple challenges in online learning platforms, the use of the text chat feature found in all videoconference platforms can help students to communicate with one another and with the instructor in a constant flow without disruption.

When a synchronous class is not an option, it is important to sustain active interactions until the online course is 
completed (Gellis, 2004). Educational resources and interactive communication strategies (Tu \& McIsaac, 2002) can also facilitate social presence. For example, Flipgrid, a popular web-based social learning platform, enables students to make brief video recordings that can be shared with the entire class. Flipgrid has myriad applications for clinical education. For example, it can be used as an alternative to written discussion boards or to record role plays of clinical scenarios. By actually seeing and hearing one another, students are more likely to feel connected to the learning experience. The resulting cohesion can motivate students to stay in online classes rather than withdraw because of lack of familiarity with online education (Galyon et al., 2016; Williams et al., 2006). Peer support and active collaboration by students can bridge the gap between in-person and online classes (Davis et al., 2019; Holmes et al., 2015). Synchronous online office hours can maintain social presence. When selecting online educational resources, social work educators should be mindful of students who require accommodations required in the Americans with Disabilities Act (as amended). Educators are encouraged to work with appropriate campus support services to provide those students necessary accommodations to ensure their success.

Online education became the "new normal" in academia during the global pandemic. However, it is not without challenges. While the majority of previous studies comparing online and traditional face-to-face courses have reported comparable effects in gaining knowledge in research, gerontology, and human behavior in the social environment (e.g., Ni, 2013; Royse, 2000; Sidell, 2006; Westhuis et al., 2006; Woehle \& Quinn, 2009), little research has been conducted on online clinical social work practice courses (Cummings et al., 2013; Petracchi et al., 2005; Siebert et al., 2006). There are still concerns in the literature about teaching clinical practice courses online in a manner that ensures that students gain necessary knowledge and skills (Forgey \& Ortega-Williams, 2016; Groshong et al., 2013). Although online classes allow students and educators to have face-toface interactions via a videoconferencing application, these interactions do not produce the same level of learning effects as those that are experienced in the classroom-based format (Davis et al., 2019; Groshong et al., 2013). Many educators and students have not been provided adequate training in using video applications (such as how to use breakout rooms for group discussions in the synchronous class session) or have not received adequate resources from their institutions (Zidan, 2015). Because students and educators are not in the same location and may not be competent in using video applications or other technology skills, major challenges related to the lack of social connection or feelings of spatial isolation have been reported by students in online classes (Sung \& Mayer, 2012). Financial constraints, access to computers (there may be one device in a house with many users), privacy, and consistent and reliable Internet signals present challenges for students in terms of online education. More research is required to examine the effects of online clinical social work practice courses and to provide empirical evidence of strategies and techniques, both synchronous and asynchronous, that are effective in emergency situations.

Acknowledgements The authors would like to acknowledge with gratitude Jeffrey Landsman-Wohlsifer, LCSW, for his insightful feedback on this article.

Author contributions As first author DBW, I worked collaboratively the LPS and JP authors to determine the concept and direction of the manuscript. I contributed small parts to the introduction and discussion sections. I wrote the following sections: Case example; Ambiguous Loss and the COVID-19 pandemic; Interpersonal Neurobiology; and Ritual and Ceremony. I provided the comments on the sections completed by other authors. I reviewed all references and the reference list for accuracy. LPS: My contribution was the Here and Now Section. As the co-author (JP), I worked collaboratively with a corresponding author and co-author to determine the concept and direction of the manuscript. I wrote the Introduction, Special challenges and issues in teaching and learning in social work practice courses, and Discussions. Finally, I provided the comments on the sections completed by other authors.

Funding Not applicable

\section{Declarations}

Conflict of interest All the authors declared that they have no conflict of interest/competing interest in relation to this manuscript.

\section{References}

Andersen, K. G., Rambaut, A., Lipkin, W. I., Holmes, E. C., \& Garry, R. F. (2020). The proximal origin of SARS-CoV-2. Nature Medicine, 26(4), 450-452. https://doi.org/10.1038/s41591-020-0820-9

Boss, P., \& Couden, B. (2002). Ambiguous loss from chronic physical illness: Clinical interventions with individuals, couples, and families. Journal of Clinical Psychology, 58(11), 1351-1360. https:// doi.org/10.1002/jclp.10083

Centers for Disease Control and Prevention. (2020). Health departments: Interim guidance on developing a COVID-19 case investigation \& contact tracing plan. Retrieved from https://www.cdc. gov/coronavirus/2019-ncov/downloads/case-investigation-conta ct-tracing.pdf

Cozolino, L. (2014). The neuroscience of human relationships: Attachment and the developing social brain ( $2 \mathrm{nd}$ ed.). Norton.

Cummings, S. M., Foels, L., \& Chaffin, K. M. (2013). Comparative analysis of distance education and classroom-based formats for a clinical social work practice course. Social Work Education, 32(1), 68-80. https://doi.org/10.1080/02615479.2011.648179

Davis, C., Greenaway, R., Moore, M., \& Cooper, L. (2019). Online teaching in social work education: Understanding the challenges. Australian Social Work, 72(1), 34-46. https://doi.org/10.1080/ 0312407X.2018.1524918

Dove, L. M. (2021). A sanctuary: Mourning the loss of the classroom during COVID. Qualitative Social Work, 20(1-2), 162-167. https://doi.org/10.1177/2F1473325020981084 
Falloon, G. (2012). Inside the virtual classroom: Student perspectives on affordances and limitations. Journal of Open, Flexible, and Distance Learning, 16(1), 108-126.

Fishbane, M. D. (2007). Wired to connect: Neuroscience, relationships, and therapy. Family Process, 46(3), 395-412. https://doi. org/10.1111/j.1545-5300.2007.00219.x

Fishbane, M. D. (2013). Loving with the brain in mind: Neurobiology \& couple therapy. Norton.

Fletcher, K. L., Comer, S. D., \& Dunlap, A. (2014). Getting connected: The virtual holding environment. Psychoanalytic Social Work, 21(1-2), 90-106. https://doi.org/10.1080/15228878.2013. 865246

Forgey, M. A., \& Ortega-Williams, A. (2016). Effectively teaching social work practice online: Moving beyond can to how. Advances in Social Work, 17(1), 59-77. https://doi.org/10. $18060 / 20877$

Galea, S., Merchant, R. M., \& Lurie, N. (2020). The mental health consequences of COVID-19 and physical distancing: The need for prevention and early intervention. JAMA Internal Medicine. https://doi.org/10.1001/jamainternmed.2020.1562

Galyon, C. E., Heaton, E. C., Best, T. L., \& Williams, R. L. (2016). Comparison of group cohesion, class participation, and exam performance in live and online classes. Social Psychology of Education, 19(1), 61-76. https://doi.org/10.1007/s11218-015-9321-y

Gangopadhyaya, A., \& Garrett, A. B. (2020). Unemployment, health insurance, and the COVID-19 recession. Robert Wood Johnson Foundation.

Gellis, Z. D. (2004). Student assessment of an online clinical social work research course: Using a collaborative learning model. Advances in Social Work, 5(1), 77-90.

Groshong, L., Mckenna, R., Hadley, S., Freeman, J., \& Kanter, J., Phillips, D., Reamer, F., \& Stephenson, D. (2013). Report on online MSW programs. Retrieved from https://www.clinicalsocialworkas sociation.org/Resources/Documents/CSWA\%20-\%20Position\% 20Paper\%20-\%20Online\%20MSW\%20Programs\%20-\%20Sep tember2013.pdf

Hodges, C., Moore, S., Lockee, B., Trust, T., \& Bond, A. (2020). The difference between emergency remote teaching and online learning. Retrieved from https://er.educause.edu/articles/2020/3/thedifference-between-emergency-remote-teaching-and-online-learn ing

Holmes, E. A., O'Connor, R. C., Perry, V. H., Tracey, I., Wessely, S., Arseneault, L., Ballard, C., Christensen, H., Silver, R. C., Everall, I., Ford, T., John, A., Kabir, T., King, K., Madan, I., Michie, S., Przybylski, A. K., Shafran, R., Sweeney, A., et al. (2020). Multidisciplinary research priorities for the COVID-19 pandemic: A call for action for mental health science. The Lancet Psychiatry, 7(6), 547-560.

Holmes, M. R., Tracy, E. M., Painter, L. L., Oestreich, T., \& Park, H. (2015). Moving from flipcharts to the flipped classroom: Using technology driven teaching methods to promote active learning in foundation and advanced masters social work courses. Clinical Social Work Journal, 43(2), 215-224. https://doi.org/10.1007/ s10615-015-0521-x

Holshue, M. L., DeBolt, C., Lindquist, S., Lofy, K. H., Wiesman, J., Bruce, H., Spitters, C., Eericson, K., Wilkerson, S., Tural, A., Diaz, G., Cohn, A., Fox, L., Patel, A., Gerber, S. A., Kim, L., Tong, A., Lu, X., Lindstrom, S., et al. (2020). First case of 2019 novel coronavirus in the United States. New England Journal of Medicine, 382, 929-936.

Hutchison, J. (2021). Applying feminist principles to social work teaching: Pandemic times and beyond. Qualitative Social Work, 20(1-2), 529-536. https://doi.org/10.1177/2F1473325020973305

Karabanow, J. (2021). A reflection on living through COVID-19 as a social work professor. Qualitative Social Work, 20(1-2), 439-442. https://doi.org/10.1177/2F1473325020973296
Kivlighan, D. (2014). Three important clinical processes in individual and group interpersonal psychotherapy sessions. Psychotherapy, 51(1), 20-24. https://doi.org/10.1037/a0032162

McCarthy, K. M., Glassburn, S. L., \& Dennis, S. R. (2021). Transitioning to online teaching: A phenomenological analysis of social work educator perspectives. Social Work Education. https://doi. org/10.1080/02615479.2020.1869206

Murphy, M. P. (2020). COVID-19 and emergency eLearning: Consequences of the securitization of higher education for post-pandemic pedagogy. Contemporary Security Policy, 41(3), 492-505. https://doi.org/10.1080/13523260.2020.1761749

Nedeva, V., Dineva, S., \& Atanasov, S. (2014). Effective e-learning course with web conferencing. Retrieved from https://www.resea rchgate.net/profile/Svetoslav_Atanasov2/publication/262566229_ Effective_E-learning_Course_With_Web_Conferencing/links/ 0f3175381dad1e9311000000.pdf

Ni, A. Y. (2013). Comparing the effectiveness of classroom and online learning: Teaching research methods. Journal of Public Affairs Education, 19(2), 199-215. https://doi.org/10.1080/15236803. 2013.12001730

Petracchi, H., Mallinger, G., Engel, R., Rishel, C. W., \& Washburn, C. (2005). Evaluating the efficacy of traditional and web-assisted instruction in an undergraduate social work practice class. Journal of Technology in Human Services, 23(3-4), 299-310. https://doi. org/10.1300/J017v23n03_09

Petzold, A. M. (2020). Letter to the Editor: Resources and recommendations for a quick transition to online instruction in physiology. Advances in Physiology Education, 44(2), 217-219. https://doi. org/10.1152/advan.00049.2020

Royse, D. (2000). Teaching research online: A process evaluation. Journal of Teaching in Social Work, 20(1-2), 145-158. https:// doi.org/10.1300/J067v20n01_09

Sapiro, B. (2021). Teaching social work practice in the shared trauma of a global pandemic. In C. Tosone (Ed.), Shared trauma, shared resilience during a pandemic (pp. 323-329). Springer.

Sethi, B. (2021). Will someone knock on my door? COVID-19 and social work education. Qualitative Social Work, 20(1-2), 116122. https://doi.org/10.1177/2F1473325020981075

Sidell, N. (2006). Teaching an elective online course in gerontology: One BSW program's experience. Journal of Baccalaureate Social Work, 11(2), 51-60. https://doi.org/10.18084/1084-7219.11.2.51

Siebert, D. C., Siebert, C. F., \& Spaulding-Givens, J. (2006). Teaching clinical social work skills primarily online: An evaluation. Journal of Social Work Education, 42(2), 325-336. https://doi. org/10.5175/JSWE.2006.200404103

Shulman, M. (2000). Developing global connections through computermediated communication. The Internet TESL Journal, 7(6), 2001.

Smoyer, A. B., O'Brien, K., \& Rodriguez-Keyes, E. (2020). Lessons learned from COVID-19: Being known in online social work classrooms. International Social Work, 63(5), 651-654. https:// doi.org/10.1177/2F0020872820940021

Sung, E., \& Mayer, R. E. (2012). Five facets of social presence in online distance education. Computers in Human Behavior, 28(5), 1738-1747. https://doi.org/10.1016/j.chb.2012.04.014

Tu, C. H., \& McIsaac, M. (2002). The relationship of social presence and interaction in online classes. American Journal of Distance Education, 16(3), 131-150. https://doi.org/10.1207/S15389286A JDE1603_2

Wang, C., Horby, P. W., Hayden, F. G., \& Gao, G. F. (2020). A novel coronavirus outbreak of global health concern. The Lancet, 395(10223), 470-473. https://doi.org/10.1016/S0140-6736(20) 30185-9

Walsh, F. (2009). Spiritual resources in family therapy (2nd ed.). Guilford.

Westhuis, D., Ouellette, P. M., \& Pfahler, C. L. (2006). A comparative analysis of on-line and classroom-based instructional formats for 
teaching social work research. Advances in Social Work, 7(2), 74-88. https://doi.org/10.18060/184

Williams, E. A., Duray, R., \& Reddy, V. (2006). Teamwork orientation, group cohesiveness, and student learning: A study of the use of teams in online distance education. Journal of Management Education, 30(4), 592-616. https://doi.org/10.1177/2F10525629 05276740

Woehle, R., \& Quinn, A. (2009). An experiment comparing HBSE graduate social work classes: Face-to-face and at a distance. Journal of Teaching in Social Work, 29(4), 418-430. https://doi.org/ $10.1080 / 08841230903249745$

Yalom, I., \& Leszcz, M. (2005). The theory and practice of group psychotherapy. Basic Books.

Zhang, J. J., Dong, X., Cao, Y. Y., Yuan, Y. D., Yang, Y. B., Yan, Y. Q., Akdis, C. A., \& Gao, Y.-D. (2020). Clinical characteristics of 140 patients infected with SARS-CoV-2 in Wuhan. China. Allergy. https://doi.org/10.1111/all.14238

Zidan, T. (2015). Teaching social work in an online environment. Journal of Human Behavior in the Social Environment, 25(3), 228-235. https://doi.org/10.1080/10911359.2014.1003733
Publisher's Note Springer Nature remains neutral with regard to jurisdictional claims in published maps and institutional affiliations.

David B. Wohlsifer, Ph.D., LCSW, is a Clinical Instructor at Florida Atlantic University, Phyllis and Harvey SandlerSchool of Social Work in Boca Raton, FL and the co-owner of the Boca Raton Center for Psychotherapy.

Laurie Patlin Suttenberg, DSW, LCSW is a Clinical Instructor at Florida Atlantic University, Phyllis and HarveySandler School of Social Work in Boca Raton, FL and is in private practice in Boca Raton, FL

Juyoung Park, Ph.D. is an Professor at Florida Atlantic University, Phyllis and Harvey Sandler School ofSocial Work in Boca Raton, FL. 